\title{
"SEDENTÁRIAS" E COQUETTES À MARGEM: CORPOS E FEMINILIDADES DESVIANTES NA OBRA DE RENATO KEHL
}

\author{
André Luiz dos S. Silva \\ Mestre em Ciências do Movimento Humano pela Universidade Federal do Rio Grande do Sul, licenciado e bacharel em \\ Educação Física pela UFV e professor no curso de Educação Física do Centro Universitário FEEVALE.
}

\section{Silvana Vilodre Goellner}

Doutora em Educação pela Unicamp, mestre em Ciências do Movimento Humano pela UFRGS, licenciada em Educação Física pela UFSM e professora na graduação e pós-graduação do Curso de Educação Física da Universidade Federal do Rio Grande do Sul.

\begin{abstract}
Resumo
Este texto fala sobre mulheres marginalizadas por dizeres normativos e disciplinares proferidos por Renato Kehl, um dos mais importantes eugenistas brasileiros. Em meio a sua obra, recortamos o período entre 1917 e 1929, para investigarmos como gesta, juntamente com a educação física, a imagem de corpos e feminilidades desviantes. Referidas como "sedentárias" e coquettes, Kehl utiliza seus corpos para lhes atribuir noções de impureza, indolência e feiúra. Em contrapartida às artimanhas das coquettes e à preguiça da sedentária, a mulher eugênica deve cultivar a beleza honesta por meio dos exercícios ginásticos - sua beleza deve ser "natural" e higiênica. Saúde, honestidade, robustez e formosura são predicados que se tornaram centrais com a marginalização de feminilidades desviantes.

Palavras-chave: educação física, eugenia e gênero - corpo - esporte - escola - lazer
\end{abstract}

\section{Introdução}

$\mathrm{E}$ ste texto fala sobre corpos não tão harmoniosos, pouco elegantes e longe da perfeição... Menciona mulheres gordas, inativas, falsas magras e, ainda, aquelas que dissimulam suas imperfeições. Seja magra! Faça ginástica! Conquiste a beleza autêntica por meio de hábitos saudáveis! Estes são alguns dos imperativos que ao serem aqui problematizados advertem os corpos acerca de suas imperfeições ao mesmo tempo em que reiteram a centralidade de corpos magros, jovens, robustos - bonitos.

As páginas que se seguem, talvez, refiram-se a mulheres "comuns", que transitam pelas ruas, leem jornais... talvez falem de mulheres dos dias hoje. Enfatizar a dúvida e a possibilidade trazidas pelo advérbio "talvez", revela que o foco deste artigo recai sobre imagens e textos que abordam o corpo feminino produzidos numa temporalidade diferente da nossa. Porém, aponta ainda, que as questões e problemas abordados neste texto estão embebidos no nosso tempo presente $(\mathrm{BLOCH}$, 2001). Mulheres dos dias de hoje fizeram-nos sensíveis a olhar para o passado e ler, nos idos 1920, dizeres sobre o corpo feminino. Elas fizeram-nos buscar seus significados e relações com a educação física e Eugenia. ${ }^{1}$

Para tanto, focamos nosso olhar nas obras do médico Renato Kehl (1889-1974), um dos mais importantes eugenistas brasileiros e autor de dezenas de livros. Em meio a sua vasta obra, recortamos o período compreendido entre 1917 e 1929, ${ }^{2}$ para investigarmos

1 Ciência gestada por volta do século XIX que prega a melhoria da espécie humana via reprodução seletiva. Sobre a Eugenia e sua constituição indicamos Stepan (2005), Diwan (2007) e Black (2003).

2 Adotamos esse período porque os textos de Kehl compreendem fases distintas. $\mathrm{O}$ ano de 1917 é considerado marco das iniciativas eugênicas de Kehl, data que proferiu na Associação Cristã de Moços (SP), sua primeira palestra sobre Eugenia. 1929 é marcado pelo lançamento de seu Lições de 
como este eugenista gesta, juntamente com a educação física, a imagem de feminilidades desviantes.

Os vestígios deixados por Renato $\mathrm{Kehl}^{3}$ foram analisados a partir do referencial teórico-metodológico da História Cultural (CHARTIER, 2001; PESAVENTO, 2003; FALCON, 2002) e de vertentes dos estudos de gênero pós-estruturalistas (LOURO, 1997; NICHOLSON, 2000; BUTLER, 2003).

Embebidos por esse referencial, analisamos sua obra, focando os corpos que se exercitam, entendendo-os como constructos sociais e históricos. Observamos suas anatomias e trejeitos, o que foi tornado visível e o que tentou esconder. Em outras palavras: ao percorrermos sua vasta obra, identificamos um compilado de idéias cuja recorrência possibilitou a emergência de rede discursiva que conferiu forma e legitimidade a determinados corpos femininos. Essa maneira de dizer sobre o corpo das mulheres nos possibilita pensar que nas obras de Renato Kehl, o gênero é uma mera extensão da diferença sexual biologicamente atribuída (GIDDENS, 1997).

Médico, farmacêutico e eugenista, Kehl gesta, no interior de suas obras discussões sobre diversos temas, dentre eles: maternidade, Educação, Higiene, Saneamento e a Educação Física. Nascido em Limeira, interior de São Paulo, formou-se em Farmácia, em 1909, pela Escola de Farmácia de São Paulo, e em Medicina em 1915, pela Faculdade de Medicina do

Eugenia, que, segundo Nalli (2000), é uma de suas obras mais importantes e polêmicas. Entre 1917 e 1929, Kehl deu a suas obras um tom muito mais "brando", caracterizando uma "Eugenia preventiva" disposta a informar e sensibilizar sobre a causa eugênica, buscando vínculos com o Saneamento, Educação e Higiene. Assim, esse período configura-se como um campo fértil e abundante em fragmentos e textos sobre as atividades físicas sistemáticas. Para maior aprofundamento sobre essa discussão indicamos Souza (2006) e Silva (2007).

3 Encontra-se na COC/FIOCRUZ, rico acervo pessoal que consta de recortes de jornal, revistas, cartas e outros, organizados e catalogados pelo próprio Kehl.
Rio de Janeiro, títulos que lhe conferiram status e o auxiliaram a dar voz à Ciência Eugenia. ${ }^{4}$

Constituída como movimento políticocientífico que visava a melhoraria da condição racial, a Eugenia estava fadada ao desenvolvimento da espécie. No Brasil, por volta do início da década de 1910, esta ciência ganhou alguns adeptos dizendo ser a salvação para o caso de multi-raças que aqui se instaurara. A herança da política escravocrata, somada à intensa imigração européia e posteriormente japonesa, fez com que os olhares da elite letrada recaíssem no desânimo. ${ }^{5}$ A Eugenia seria a ciência capaz de curar os males produzidos pela miscigenação, pelo negro, pelo índio, pelos italianos e japoneses. Muito mais que regenerar racialmente a população brasileira, a Eugenia carregava, em seus preceitos, ares de um civismo europeu que aportaria neste país para endireitar corpos e embelezar o povo.

As investidas dessa Ciência, no Brasil, começam a surgir, de forma mais sistemática, por volta da segunda metade da década de 1910. Em 1918, Renato Kehl, juntamente com Arnaldo Vieira de Carvalho, funda a Sociedade Eugênica de São Paulo, um marco do movimento eugênico brasileiro e importante conquista de Kehl em direção a seu projeto de vulgarização dessa Ciência.

Nesse período foram editados seus primeiros livros cujos conteúdos estão encharcados de ensinamentos, valores e normas ${ }^{6}$ morais daquele tempo. Nos primeiros anos da década $1920,{ }^{7}$ Kehl, nos textos que produziu

4 Para maiores apontamentos sobre a vida de Renato Kehl indicamos Souza (2006).

5 Sobre este aspecto indicamos Reis (1994).

6 Concebo que os termos "norma”, "normal", anormal" e suas variantes configuram-se como importantes conceitos nas obras de Canguilhem (2000), Foucault (2007) e Costa (1999), carregando particularidades de seus referenciais. Neste texto, entretanto opto por não operar com esses conceitos.

7 Segundo indicações bibliográficas organizadas pelo próprio Kehl, em 07/02/1917 foi publicado, no Jornal do Comércio, um texto de sua autoria com o título "A cultura physica". No garimpo das fontes não foi possível acessar esse artigo. Dentre as fontes consultadas, Renato Kehl volta a falar sobre 
sobre a educação física, imprime, juntamente com as leis "naturais" do crescimento e desenvolvimento, da Fisiologia e da hereditariedade, elementos disciplinares, modos de ser e de se portar. Suas obras revelam-se tal qual um compêndio pedagógico que ensina pressupostos de raça, classe, gênero, constituindo, assim, modos de ser homens, mulheres, mães, pais, filhos, cidadãos... Autorizado pela competência médica e pelas relações político-intelectuais que construiu, ${ }^{8}$ este eugenista elege como referentes os corpos de mulheres belas, magras e elegantes, localizando nas margens as gordas, inativas e falsas.

\section{Indolente, gorda, vulgar - feia: Corpos desviantes, feminilidades à margem}

Quatro são as condições essenciaes para a belleza do corpo humano e, todas ellas influenciadas, de modo rápido e incisivo, pelos exercícios gymnasticos; o esqueleto, a musculatura, a gordura e a pelle. [...]

Esqueleto, musculatura, gordura e pelle reclamam, para a sua melhoria e conservação, a gymnastica, não gymnastica de força, mas gymnastica de movimento, de agilidade e de graça, gymnastica callisthenica; em-fim natação, dansas estheticas, jogos ao ar livre etc. (KEHL, 1927, p.19-20).

Nos textos de Kehl os vínculos estabelecidos entre os exercícios físicos e os corpos das mulheres, evidenciam a beleza como elemento central, seja na exposição de belos corpos, seja nos conselhos para sua aquisição/manutenção, ou mesmo nos preciosismos da simetria.

Em meio aos seus escritos são recorrentes as representações femininas gestadas a partir de esculturas gregas. As Vênus impressas nos textos que abordam as atividades físicas dão

a educação física em 14 de agosto de 1920, em um artigo publicado em O Jornal, intitulado "Exercícios physicos". Nesse texto, discute a obra Da educação physica, publicada em 1920, por Fernando de Azevedo. A partir de então, educação física torna-se assunto corrente nos textos de Kehl contidos no recorte deste estudo - até 1929 (SILVA, 2008).

8 Sobre essa relação ver Souza (2006). forma aos imperativos da pele lisa e bran$\mathrm{ca}$, das coxas bem torneadas, do abdômen e das "ancas" firmes, resultado da apropriada exercitação física. A Grécia antiga, em suas perfeições, é reiterada nos corpos de Vênus, Afrodite, Helena e tantas outras, projetando neles a beleza sublime, a delicadeza dos gestos e a perfeição inalcançável.

Essas imagens são inseridas em meio a inúmeros dizeres que reforçam as obrigações femininas com a beleza, tornando-se emblema do vir a ser, apontando para as imperfeições corporais, presentificando a fealdade. Tal estratégia problematizaria as mulheres e seus corpos, indicando diversidade e instabilidade, marginalizando-as por não cumprirem com suas obrigações - serem belas.

Pouca gente sabe o que seja uma "bella mulher". A maioria tem, sobre plastica, idéa errônea e confusa. Uma jovem, por ter alguns encantos é logo considerada formosa. Ha nisso engano. A belleza é rara. Mesmo na excelsa pátria hellenica, [...] não se contavam em grande número as Aspasias, as Lais, as Phrynéas. Ser bella implica reunir num corpo de deusa as fórmas magníficas de Aphrodite. Raras, raríssimas as mulheres que podem ter a pretensão de serem rainhas da plastica, possuindo, a rigor, as justas proporções das partes, harmonia de linhas, esbeltez do talhe, delicadeza de contornos, epiderme rosada e fina, além dos predicados indispensáveis de saúde e robustez $^{9}$ (KEHL, 1927, p. 15-16).

Fragmentos como este aparecem em diversos momentos, indicando a beleza como algo que as mulheres não possuem, mas devem alcançar, evidências que ganham mais vulto quando postas ao lado de tabelas e quadros que revelam a proporcionalidade "normal" dos corpos femininos. ${ }^{10}$

9 Com algumas adaptações este fragmento já havia sido publicado como parte de um capítulo intitulado "Belleza", contido em seu Bíblia da saúde (1926).

$10 \mathrm{O}$ autor busca em Georges Hébert, especialmente em sua obra Muscle et beauté plastique, elementos que reforcem, com exemplos, a normalidade das proporções do corpo. Diversas imagens de textos de Hébert são utilizadas por 
Assim, Kehl elege em suas obras a beleza feminina como dever de toda mulher, responsabilizando-as por valorizar seus dotes físicos para apresentarem-se sempre formosas, mesmo que para isso seja necessário disfarçar seus possíveis sinais de imperfeição. Algumas dessas regras foram organizadas e contempladas em uma obra especialmente destinada a discutir um Formulário de belleza (1927). Para Kehl, este livro foi:

[...] despretensiosamente lançado ao público, sem outro intuito que o de ser útil aos que o folhearem na esperança de encontrar atrativos para o próprio realce ou recursos para dissimular lamentáveis descuidos (KEHL, 1927, s. p.).

Em A cura da fealdade (1923), outro livro que se destina a falar da beleza e da feiúra humana, Kehl aponta algumas doenças e deformidades que podem acometer os leitores, ressaltando as interações medicinais para o seu tratamento, conselhos que permitiram dizer que esse livro seria:

Uma obra modernamente preciosa, contendo todos os ensinamentos para a cura da fealdade e para o realce e conservação da formosura. Aproveita, pois, a todos, aos feios e aos bellos, sobretudo às bellas que encontrarão neste livro as mais sabias receitas para a conservação da pelle e correcção dos seus pequenos senões plásticos. ${ }^{11}$

A normalidade traduzida como beleza seria a coroação dos pressupostos eugênicos, atributo, entretanto, muito raro em um país de mestiços, sujos e aleijões. "[...] a saúde, a robustez e a belleza não só se herdam, como se conservam e se adquirem pelo esforço e

Kehl especialmente em Formulário da belleza (1927) e $A$ cura da fealdade (1923). Sobre a obra de Hébert indicamos a leitura de Soares (2003).

11 Este trecho sobre a apreciação da obra $A$ cura da felicida$d e$ foi retirado de um recorte avulso encontrado no Fundo Pessoal de Renato Kehl. pela vontade" (KEHL, 1923, p. 325). É neste sentido que Kehl se propõe a discutir, em alguns de seus textos, possibilidades de embelezamento, via artifício. Composto por mais de quinhentas páginas muito bem ilustradas, em um volume de capa dura, $A$ cura da fealdade (1923) constitui-se uma das obras mais caras desse autor. ${ }^{12}$ Impelido pelo sucesso inesperado dessa obra, Kehl escreve Formulário da belleza (1927), obra assumidamente voltada para o público feminino, cujo conteúdo trata, dentre outras coisas, de receitas para o combate dos mais diversos tipos de inconvenientes físicos: "Anemia", "Boqueira", "Pernas e braços peludos", "Brilhantinas", "Cárie dentária”, "Caspas", "Cólicas menstruaes", "Dentifrícios", "Diarrhéa", "Eczemas”, "Água de Colônia", "Flatulência", "Furunculose", "Gengiva descarnada", "Lavagens intestinaes", "Magreza", "Obesidade", "Picadas de insectos", "Pomadas", "Prurido", "Sapinho", "Sarna", "Sinusites", "Supositório calmante", "Urticária", "Varizes", "Vermes intestinaes", "Verrugas" etc. Receitas de pastas, pós antissépticos e escoriações da pele constituem algumas fórmulas artificiais que poderiam corrigir imperfeições, dissimulando, assim, algumas imprevidências de ordem hereditária.

Os exercícios físicos são invocados como um elixir, capaz de resolver problemas pulmonares, circulatórios, ortopédicos, assim como obesidade, anemia, preguiça, além de inúmeras moléstias enfeiantes. As técnicas e remédios, ${ }^{13}$ dentre eles, a educação física, não deveriam, entretanto, ser executados aleatoriamente. A conquista da beleza poderia gerar riscos à saúde, exigindo que o uso de artifícios fosse dosado e indicado por aqueles que detinham o saber legítimo. Ao lado de menções de cautela, artifícios fazem parte dos dizeres

\footnotetext{
12 "É um livro apparentemente caro - mas baratíssimo se attendermos aos enormes proveitos que o consulente nelle colherá." (Apreciação da obra A cura da felicidade - recorte avulso).

13 Sobre as concepções de feiúra como doença, indicamos Sant'Anna (2005).
}

PENSAR A PRÁTICA 11/3: 251-259, set./dez. 2008 
deste eugenista. A mulher deve procurar realçar sua beleza, lapidando seu próprio corpo; entretanto é preciso ter cuidado ao usar produtos e fórmulas de beleza, podendo pender ao exagero, ocasionando riscos para a saúde e para a moral.

Augmentar os próprios encantos, corrigir-lhe as falhas, preoccupar-se com os toucados, com os perfumes, com o trato da pelle e unha, é legitima demonstração de "bom tom", de esmero, de apuramento. Isto, claro está, emquanto não ultrapassar certos limites, como fazem muitas jovens, cujo dia é consumido em maquiagens, em tingimentos, em retocamentos de pálpebras e lábios transformando-se em verdadeiras bonecas de modistas (KEHL, 1925, p. 82-83).

Estes dizeres devem acompanhar os homens, avisando-os dos perigos das mulheres artificiais; devem, sobretudo, materializaremse nos corpos daquelas que se dizem sérias e honestas no cultivo de sua própria beleza. Extraído do livro Como escolher uma boa esposa (1925), o fragmento anterior aponta o embelezamento feminino como um cuidado necessário, mas não em demasia; afinal, poderia tornar-se vulgar, não representando indícios de boa esposa, ou de boa mãe.

As receitas para o embelezamento artificial são problematizadas pela constante desqualificação das mulheres que as utilizam de modo indiscriminado. Materializadas nos corpos das "Coquettes", Kehl refere-se a elas de forma pejorativa, tentando vincular ao excesso de artifícios, uma moral suspeita. Citando Latino Coelho, ${ }^{14}$ ele refere que:

[...] a mulher coquette - mulher artificial, mulher multiforme tem um coração para cada homem, uma sensibilidade para cada palavra, um trejeito para cada sentimento; assim como um vestido para cada baile, uma paixão para cada polka, um amor para valsa (LATINO COELHO apud KEHL, 1925, p. 80).

14 Escritor português.
A moda das coquettes referia-se aos costumes, modos de ser e se vestir franceses que, naquele momento, serviam de espelho para tantas outras que aspiravam ser e estar em Paris. Ao mesmo tempo em este "estilo de vida" ${ }^{15}$ sugestionava ares de modernidade e auto-afirmação, apontava também para uma moral vulgar, beirando a má vida, à prostituição (GOELLNER, 2003).

As mulheres coquettes são, sobretudo, rainhas na arte de dissimular, falseiam suas imperfeições do rosto com pó-de-arroz ou lápis crayon, disfarçam as deselegâncias do corpo com alguns truques, tornando-se, assim, artificiais ou ainda "falsas divindades da belleza".

A mulher não deve ser uma dissimuladora, deve cultivar em seu corpo a beleza natural, construída a partir dos estímulos fisiológicos, uma beleza de dentro para fora que enrubesce o rosto, não com tinturas e maquiagens, mas com o aumento de glóbulos vermelhos. As atividades físicas sistemáticas são invocadas como elemento central no processo de embelezamento, dotando o corpo de belos atributos, uma técnica que compartilha das regras gerais da Higiene, representando importante auxílio à saúde da população.

[...] o segredo da belleza do corpo feminino, representada pela estatuária antiga, está em que seus modelos possuíam o collete muscular natural, em vez do inquisitorial espartilho moderno (KEHL, 1927, p. 17).

Em outra passagem, Kehl afirma:

Como estheta, proclamo a necessidade da gymnastica entre as meninas e as jovens, único recurso para alcançar o ideal da belleza, pelo equilíbrio das partes e harmonia de todo o corpo [...] (KEHL, 1927, p. 19).

15 A coquette é descrita por Renato Kehl como uma mulher que assume a opção por hábitos, modos de ser, de se vestir, entre outros, caracterizando-as como um grupo. As sedentárias, que abordo mais adiante, de maneira diferente, são descritas como indolentes ou ignorantes, não sendo capazes nem mesmo de assumir uma posição, ao contrário, deixamse levar pela letargia. 
Concebida como elemento primordial no processo embelezamento, a ginástica tornearia as pernas, consumiria o excesso de gordura, emagreceria as "ancas" e o pescoço, cultivaria a robustez, a agilidade e a flexibilidade dos quadris, desenvolveria o equilíbrio, materializando nos corpos as 'benesses' do disciplinamento. Os artifícios, muito utilizados pelas coquettes deveriam, quando muito, ser coadjuvantes, auxiliares na constituição da beleza. Nesse sentido o autor aponta:

A legitima preservadora da belleza, o mais poderoso elemento retardante da velhice $[. .$. consiste porém na vida sadia, sob os cuidados da hygiene: na pratica diuturna da gymnastica, como methodo e moderação, - factores esses seguros para collorir as faces, não pelo carmim que desmaia e mancha, mas pela multiplicação e resistência dos glóbulos vermelhos do sangue.

Como auxiliar dessa therapeutica precisa e efficaz, admittem-se os recursos preconizados por Ovídio, dos artifícios de toucador, dos cremes, das pomadas, das loções, das tinturas, [...] (KEHL, 1927, s. p.).

Apesar de a mulher coquette, em suas artimanhas ser constantemente invocada em alguns textos de Kehl, naqueles em que o autor aborda a educação física, não se torna o único contra-exemplo. A imagem da inatividade, da mulher sedentária ${ }^{16}$ também ajuda a constituir a obrigação da beleza e ressaltar o tipo de corpo considerado eugenicamente normal. Muito mais vinculada à falta de atitude do que a um estilo de vida, a sedentária é evidenciada em meio aos "seios pendentes", "carnes moles", "excesso de gordura", "ventre abaulado", "braços gordos e roliços", "quadris exuberantes de tecido adiposo"... Ao lado das mulheres artificiais, Kehl pinta a repugnante mulher seden-

16 Atualmente há um profícuo debate acerca do sedentarismo, uma discussão que possui sentidos próprios do nosso tempo; a esse respeito indicamos Fraga (2006). Neste texto, deixamos Renato Kehl atribuir sentidos a esse termo. Convidamos, assim, o leitor a pensar a mulher sedentária, a partir dos contornos dados por esse eugenista. tária, evidenciando o corpo daquelas que se esforçam, dentro dos preceitos higiênicos e eugênicos, para constituírem seus corpos belos.

Segundo ele, as mulheres, por sua "natureza”, eram mais propícias ao sedentarismo, optando por ficar em casa a desfrutarem de um "salutar passeio à pé". Vivendo entre quatro paredes, ao abrigo da luz e do ar puro, as mulheres definham, pouco a pouco, na sua inatividade. Os avanços dos meios de locomoção mantinham as mulheres presas ao vício do sedentarismo; seja de bonde ou automóvel, muitas se negavam a caminhar, cultivando a adiposidade e a flacidez muscular.

$\mathrm{Na}$ justa contraposição, os exercícios físicos surgem como forma de evitar o envelhecimento, intensificar a vida, estimular músculos, ossos e glândulas e, sobretudo, desenvolver a beleza.

[...] o poder muscular é a resistência às fadigas e às doenças, o enrijamento para as intempéries; é a velocidade dos movimentos, a dextreza, a energia; é, emfim, a aptidão para todos os gêneros de exercícios naturaes e utilitários (KEHL, 1923, p. 78).

A ignorância, a indolência e as idéias erradas sobre os exercícios físicos estariam afastando-as de tão benéfica atividade. Muito mais sujeitas ao acúmulo de gordura que os homens, as mulheres, em especial, as casadas, as que se aproximam da velhice e, ainda, aquelas que já deram à luz o primeiro filho, compõem o triste quadro da deformidade ventral. Músculos flácidos, somados à "hypertrophia gordurosa", conformam quadris demasiadamente largos, abdomens pendentes e seios flácidos. Como forma de evitar, amenizar ou até mesmo solucionar tais problemas, as ginásticas são indicadas às mulheres. Em meio aos dizeres de Kehl, as sedentárias ocupam um lugar especial no processo de convencimento em favor dos exercícios físicos.

Como exemplo daquilo que não se deve ser, esse eugenista evidencia, com adjetivos pejorativos, partes do corpo da mulher sedentária. "Musculatura atrophiada", "espáduas 
angulosas" e "seios cahidos" são associados a poses e feições típicas de uma mulher vulgar, compondo um quadro que serve de contraexemplo. A imagem da mulher sedentária, traduzida em exemplo de como não se deve ser, povoa os seus textos cuja narrativa, reiteradamente, promove a graça, a beleza e a feminilidade daquelas que se movimentam.

\section{Considerações finais}

Aos corpos das "sedentárias" e coquettes, Kehl atribui noções de impureza, indolência e feiúra. Rainhas da arte de dissimular, as coquettes falseiam suas imperfeições, disfarçam as deselegâncias do corpo com truques, tornando-se assim "falsas divindades de belleza". Kehl aponta os corpos dessas mulheres como representantes da falsidade, indícios de uma moral vulgar - exemplo daquilo que não se deve ser. A inatividade, característica das dissimuladoras da beleza, também diz respeito ao corpo das "sedentárias", mulheres "preguiçosas", gordas, pálidas e feias. Com os "quadris super-lotados", "seios flácidos" e "pernas roliças”, as sedentárias são apontadas como anti-higiênicas e doentes, seres à margem dos atributos eleitos para uma mulher eugênica.

"Sedentárias" e coquettes desfilam por este texto carregando em seus corpos as marcas da marginalização, apontam para o significado que se atribuía, naquele contexto histórico e cultural, para a mulher eugenizada. As palavras e as imagens produzidas por Renato Kehl, acerca dos corpos femininos representados como marginais, excêntricos, periféricos contém, ainda, uma dupla perspectiva: ora os menciona de forma a evidenciar seu caráter imperfeito para nomear o corpo masculino como referente, ${ }^{17}$

17 Em estudos anteriores foi possível perceber que Renato Kehl confere centralidade ao corpo masculino eugenizado a partir de referências femininas e masculinas desviantes. Neste texto, optamos por não abordar o referente masculino para enfatizarmos a forma como Kehl hierarquiza os corpos e as feminilidades. Sobre esse aspecto indicamos Silva (2008). ora desenha os contornos de mulheres excêntricas para hierarquizar tipos distintos de feminilidades.

Ao optarmos por evidenciar as hierarquias que Kehl atribui às feminilidades, percebemos que com o anseio de construir corpos femininos dentro de parâmetros eugênicos, o autor opta por desqualificar seus contra-exemplos. A imagem de "outras" mulheres seria importante para reiterar a superioridade e centralidade daquelas que possuem a justa conformação das carnes, que incorporam hábitos higiênicos e que manifestam a perfeição moral.

Renato Kehl se debruça a falar daquelas que foram por ele posicionadas fora do centro, ${ }^{18}$ indicando normas de condutas, práticas cotidianas, receitas e fórmulas de vida saudável, marginalizando aquelas que não se exercitam fisicamente, aquelas que não são honestamente belas.

Ao contrário das artimanhas da coquette e da indolência da sedentária, a mulher eugênica deve cultivar em seu corpo a beleza honesta por meio de estímulos fisiológicos dos exercícios ginásticos - sua beleza deve ser "natural" e higiênica. Saúde, honestidade, robustez e formosura são predicados que se tornaram centrais com a marginalização de feminilidades desviantes.

\section{Sedentary and coquette women on the margin: \\ deviant femininity in renato kehl's works}

\section{Abstract}

This article discusses women who were marginalized by normative and disciplinary discourses uttered by by Renato Kehl, one of the most important Brazilian eugenicists. Among his works, we selected the ones produced between 1917 and 1929 in order to investigate how his work, together with physical education, helped conceive the image of deviating bodies and femininity. Referred to as "sedentary" and "coquettes", Kehl used the images of their bodies to attach notions of impurity,

18 Sobre esse tema ver Louro (2003), onde a autora desenvolve uma discussão acerca das formas como a nossa cultura estabelece o que é considerado o normal, o diferente e o excêntrico, nomeando os referentes (aqueles colocados no centro) e os desviantes (aqueles colocados à margem). 
indolence, and ugliness to them. In opposition to coquettes' craftiness and to sedentary women's laziness, the eugenic woman should cultivate honest beauty by performing physical exercises - her beauty should be "natural" and hygienic. Health, honesty, vigor and beauty are attributes that have become central due to the marginalization of deviating femininity.

Keywords: Physical Education, Eugenics and Gender Body - Sport - School - Leisure

"Sedentarias" y "coquettes" marginadas: cuerpos y femininad con desvío en la obra de renato kehl

\section{Resumen}

Este texto habla sobre mujeres marginadas por discursos normativos y disciplinares proferidos por Renato Kehl, uno de los más importantes defensores de la Eugenesia brasileña. En medio a su obra, recortamos el período entre 1917 y 1929, investigando, juntamente con la educación física, la imagen femenina con desvío. Referidas como "sedentarias" y "coquettes", Kehl utiliza sus cuerpos atribuyéndoles nociones de impureza, indolencia y fealdad. En contrapartida a las artimañas de las "coquette", y a la pereza de la sedentaria, la mujer eugenesia debe cultivar la belleza honesta por medio de los ejercicios gimnásticos - su belleza debe ser "natural" y higiénica. Salud, honestidad, robustez y hermosura son predicados que se tornaron centrales con la marginalización de femenina con desvíos.

Palabras-clave: Educación Física, "Eugenia” y Género - Cuerpo - Deporte - Escuela - Ocio

\section{Referências}

AZEVEDO, F. de. Da educação physica. São Paulo/Rio de Janeiro: Weiszflog Irmãos, 1920.

BLACK, E. A guerra contra os fracos. São Paulo: A Girafa, 2003.

BLOCH, M. Apologia da história, ou, o oficio do historiador. Rio de Janeiro: Jorge Zahar, 2001.

BUTLER, J. Problemas de gênero: feminismo e subversão da identidade. Rio de Janeiro: Civilização Brasileira, 2003.

CANGUILHEM, G. O normal e o patológico. 5. ed. Rio de Janeiro: Forense Universitária, 2000.
CHARTIER, R. Textos, impressão, leitura. In: HUNT, L. (Org.) A Nova História Cultural.2. ed. São Paulo: Martins Fontes, 2001.

COSTA, J. F. Ordem médica e norma familiar. 4. ed. Rio de Janeiro: Graal, 1999.

DIWAN, P. S. Raça pura: uma história da Eugenia no Brasil e no mundo. São Paulo: Contexto, 2007.

FALCON, F. J. História cultural: uma visão sobre a sociedade e a cultura. Rio de Janeiro: Campos, 2002.

FOUCAULT, M. Microfísica do poder. 24. ed. São Paulo: Graal, 2007.

FRAGA, A. B. Exercício da informação: governo dos corpos no mercado da vida ativa. Campinas: Autores Associados, 2006.

GIDDENS, A. Modernidade e identidade pessoal. Oeiras: Celta, 1997.

GOELLNER, S. V. Bela, maternal e feminina: imagens da mulher na Revista Educação Physica. Ijuí: Unijuí, 2003.

KEHL, R. F Formulário da belleza: fórmulas escolhidas. Rio de Janeiro: Francisco Alves, 1927.

Bíblia da saúde (bygiene). Rio de Janeiro: Francisco Alves, 1926.

Como escolher uma boa esposa. Rio de Janeiro: Pimenta de Mello, 1925.

A cura da fealdade: Eugenia e medicina social. São Paulo: Monteiro Lobato \& CoEditores, 1923.

Exercícios physicos: a propósito do livro do Dr. Fernando de Azevedo. O Jornal, Rio de Janeiro, 14 ago. 1920. (Recorte avulso, Fundo Renato Kehl - DAD/COC).

LOURO, G. L. Gênero, sexualidade e educação: uma perspectiva pós-estruturalista. Petrópolis: Vozes, 1997.

Currículo, gênero e sexualidade: o "normal", o "diferente" e o "excêntrico". In: 
GOELLNER, S. V.; FELIPE, J.; LOURO, G. L. Corpo, Gênero e sexualidade: um debate contemporâneo na educação. Petrópolis: Vozes, 2003.

NALLI, M.. O gene educado: a antropologia eugênica de Renato Kehl e a educação. 2000. 164. f. Dissertação (Mestrado em Educação) - Faculdade de Educação, Universidade Estadual de Maringá, Maringá, 2000.

NICHOLSON, L. Interpretando Gênero. Revista Estudos Feministas, Florianópolis, v. 8, n. 2, p. 9-42, 2000.

PESAVENTO, S. J. História E história cultural. Belo Horizonte: Autêntica, 2003.

REIS, J. R. F. Higiene mental e Eugenia: o projeto de "regeneração nacional" da Liga Brasileira de Higiene Mental (1920-30). 1994. 353 f. Dissertação (Mestrado em História) - Instituto de Filosofia e Ciências Humanas, Universidade Estadual de Campinas, 1994.

SANT'ANNA, D. B. Cuidados de Si e embelezamento feminino: fragmentos para uma história do corpo no Brasil. In: SANT'ANNA, D. B. (Org.) Políticas do Corpo: elementos para uma história das práticas corporais. 2. ed. São Paulo: Estação Liberdade, 2005.

SILVA, A. L. Entre Lamarck e Mendel: olhares eugênicos sobre a Educação Física. In: GOELLNER, S.; JAEGER, A. (Orgs.) $G a-$ rimpando Memória. Porto Alegre: Editora da UFRGS, 2007.
A perfeição expressa na carne: a educação física no projeto eugênico de Renato Kehl (1917 a 1929). 2008. 141. f. Dissertação (Mestrado em Ciências do Movimento $\mathrm{Hu}-$ mano) - Escola Superior de Educação Física, Universidade Federal do Rio Grande do Sul, Porto Alegre, 2008.

SOARES, C. L. Georges Hébert e o método natural: uma nova sensibilidade, nova educação do corpo. Revista Brasileira de Ciências do Esporte, Campinas, v. 25, n. 1, p. 21-40, set. 2003.

SOUZA, V. S. A politica biológica como projeto: a "Eugenia Negativa" e a construção da nacionalidade na trajetória de Renato Kehl (1917-1932). 2006. 220 f. Dissertação (Mestrado em História das Ciências) - Programa de Pós-graduação da COC/Fiocruz, Fundação Oswaldo Cruz, Rio de Janeiro, 2006.

STEPAN, N. L. A hora da Eugenia: raça, gênero e nação na América Latina. Rio de Janeiro: Fiocruz, 2005.

Recebido em: 30/09/2008

Revisado em: 16/11/2008

Aprovado em: 26/11/2008

\section{Endereço para correspondência}

andrels@feevale.br

goellner@terra.com.br 